\title{
Elective primary aortic root replacement with and without hemiarch repair in patients with no previous cardiac surgery
}

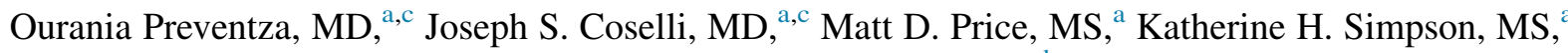
Ouyang Yafei, BS, ${ }^{\mathrm{a}}$ Kim I. de la Cruz, MD, ${ }^{\mathrm{a}, \mathrm{c}}$ Qianzi Zhang, MPH, ${ }^{\mathrm{b}}$ and Susan Green, $\mathrm{MPH}^{\mathrm{a}}$

\section{ABSTRACT}

Objective: Excellent outcomes have been established for elective aortic root replacement (ARR). It is less clear whether extending the repair into the proximal aortic arch with hypothermic circulatory arrest increases risk. We examined the early outcomes of elective, primary ARR, with and without hemiarch replacement, in patients without previous cardiac surgery.

Methods: Over a 4-year period, 140 non-redo patients (median age, 54 years) underwent elective, primary ARR for root aneurysms; 119 patients $(85 \%)$ had hemiarch replacement, and $21(15 \%)$ had only ascending aortic replacement. Valve-sparing ARR was performed in 41 cases $(29.3 \%)$ and valve-replacing ARR in $99(70.7 \%)$. Moderate hypothermic circulatory arrest and antegrade cerebral perfusion were used in $118(99 \%)$ hemiarch repairs.

Results: There were no operative deaths or permanent strokes. Complications included temporary renal dialysis $(\mathrm{n}=1 ; 4.8 \%)$, transient neurologic deficit $(\mathrm{n}=2 ; 9.5 \%)$, and tracheostomy $(\mathrm{n}=2 ; 9.5 \%)$ after ascending aortic repair and bleeding requiring reoperation $(n=4 ; 3.4 \%)$, pericardial effusion requiring drainage $(\mathrm{n}=9 ; 7.6 \%)$, and tracheostomy $(\mathrm{n}=2 ; 1.7 \%)$ after hemiarch replacement. No stroke was observed in the hemiarch group $(P=.022$; univariate analysis). The extent of the repair into the proximal arch did not appear to be associated with any adverse effect.

Conclusions: In non-redo patients, elective primary ARR has excellent early outcomes, regardless of whether repair extends into the proximal arch. Additional elective hemiarch replacement with moderate hypothermic circulatory arrest and antegrade cerebral perfusion has a low risk of neurologic complications and should be performed if necessary. Long-term data are needed to compare the rates of reintervention in the aortic arch in patients with or without proximal arch replacement. (J Thorac Cardiovasc Surg 2017;153:1402-8)

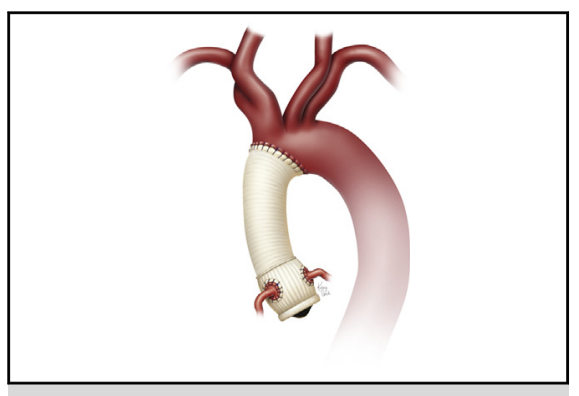

Aortic root (modified Bentall) and proximal arch replacement.

\section{Central Message}

In non-redo patients, elective primary aortic root replacement has excellent early outcomes, regardless of whether repair extends into the proximal arch.

\section{Perspective}

Excellent outcomes have been established for elective aortic root replacement. It is less clear whether extending the repair into the proximal aortic arch with hypothermic circulatory arrest increases risk. In non-redo patients, elective primary aortic root replacement has excellent early outcomes, regardless of whether repair extends into the proximal arch. Comparing reintervention rates in the aortic arch is important to determine the value of hemiarch replacement.

See Editorial Commentary page 1409.
Aortic root replacement (ARR) addresses aneurysmal pathology of the aortic root and the ascending aorta. If the aneurysm is not excised fully, distal progression of aneurysmal disease may later necessitate more extensive reoperation. ${ }^{1-3}$ For disease extending into the proximal arch, additional hypothermic circulatory arrest

From the Divisions of ${ }^{\mathrm{a}}$ Cardiothoracic Surgery and ${ }^{\mathrm{b}}$ Biostatistics, Michael E. DeBakey Department of Surgery, Baylor College of Medicine; and ${ }^{\mathrm{c} D e p a r t m e n t}$ of Cardiovascular Surgery, Texas Heart Institute, Houston, Tex.

Received for publication March 23, 2016; revisions received Oct 3, 2016; accepted for publication Oct 20, 2016; available ahead of print Dec 7, 2016

Address for reprints: Ourania Preventza, MD, 6770 Bertner St C-330, Houston, TX 77030 (E-mail: opsmile01@aol.com).

0022-5223/\$36.00

Copyright (c) 2016 by The American Association for Thoracic Surgery

http://dx.doi.org/10.1016/j.jtcvs.2016.10.076
(HCA) — which is required in the initial operation for performing an open distal anastomosis for hemiarch replacement-raises the risk for adverse outcomes, including death or permanent or temporary neurologic dysfunction. ${ }^{4}$ HCA lasting 25 minutes or more has been associated with memory problems and fine motor deficits. Because of these concerns, the optimal extent of proximal ascending aortic reconstruction in patients who require elective ARR for aortic root pathology is not clear. In our

Scanning this QR code will take you to a procedural video. 


\section{Abbreviations and Acronyms \\ ACP = antegrade cerebral perfusion \\ ARR = aortic root replacement \\ $\mathrm{BAV}=$ bicuspid aortic valve \\ $\mathrm{CABG}=$ coronary artery bypass grafting \\ $\mathrm{CPB}=$ cardiopulmonary bypass \\ $\mathrm{CVG}=$ composite valved graft \\ HCA = hypothermic circulatory arrest \\ IQR = interquartile range}

study, we focused on the safety of hemiarch replacement in patients with no previous cardiac surgery who were undergoing elective aortic root surgery. We have described the short-term outcomes of these patients and of patients who underwent ascending aortic replacement alone as part of their non-redo, elective, primary surgical ARR.

\section{PATIENTS AND METHODS}

Over an approximately 4-year period (January 2011-April 2015), 140 patients with simultaneous ascending aortic aneurysms without dissection underwent elective, primary aortic root operations at our institution. The patients' median age was 54 years (interquartile range [IQR] 25\%-75\%, 43-61 years; range, 15-81 years, with male predominance $[n=111$; $79.3 \%]$ ). None of the patients had undergone previous cardiac surgery. Of the 140 patients, 119 underwent concomitant hemiarch replacement, and 21 patients had only their ascending aorta replaced during the aortic root procedure. Data were collected from a prospectively maintained database, and the institutional review board at Baylor College of Medicine (Houston, Tex) approved the retrospective study. Follow-up information concerning adverse events was obtained mainly from clinic visits, telephone calls, records from the offices of referring physicians, and the Social Security Death Index. It should be noted, however, that the data were not based only on the latter because of the current limitations of the Social Security Death Index.

The patients' preoperative characteristics are shown in Table 1. Intraoperative variables are shown in Table 2. Operative mortality was defined as death before hospital discharge or within 30 days of discharge. Postoperative stroke was defined as a new brain injury that was clinically or radiographically evident after the procedure. Permanent or persistent stroke was defined as stroke with no recovery at the time of hospital discharge. Transient stroke was defined as stroke with full recovery at hospital discharge. Renal injury in the postoperative period was defined as needing to start dialysis or a doubling of the patient's serum creatinine level. Persistent renal injury was defined as requiring hemodialysis at hospital discharge.

Because of the small number of postoperative adverse events, composite adverse outcome was defined as transient stroke, renal failure with transient hemodialysis, postoperative renal insufficiency, postoperative bleeding requiring operation, pericardial effusion requiring drainage, and tracheostomy.

The antegrade cerebral perfusion (ACP) time was defined as the period (during circulatory arrest) in which the patient was receiving ACP. The total circulatory arrest time was the time with and without ACP. The cardiopulmonary bypass (CPB) time was the period of CPB not including the ACP time or the circulatory arrest time. The myocardial ischemic time was the time from the initiation of circulatory arrest or crossclamp placement until clamp removal. When only the ascending aorta was replaced, the myocardial ischemic time was equal to the aortic crossclamp time.

\section{Surgical Technique}

In all patients, the procedure was performed via a median sternotomy with $\mathrm{CPB}$. In the patients who underwent aortic root and hemiarch repair, the following cannulation sites were used for arterial inflow: innominate artery $(\mathrm{n}=104)$, right axillary artery $(\mathrm{n}=11)$, right subclavian artery via a median sternotomy $(\mathrm{n}=2)$, right common carotid artery $(\mathrm{n}=1)$, and side arm of the Dacron graft $(n=1)$. In the patients who underwent aortic root and ascending aortic repair only, the arterial cannulation sites were the distal ascending aorta $(\mathrm{n}=9)$, innominate artery $(\mathrm{n}=7)$, right axillary artery $(n=3)$, and femoral artery $(n=2$; these 2 patients had Marfan syndrome with severe pectus excavatum). The decision to proceed with hemiarch versus only ascending aortic replacement during the primary root operation was based on the following considerations: If the diameter of any section of the distal ascending aorta measured $\geq 4.5 \mathrm{~cm}$ or the rate of growth was more than $0.5 \mathrm{~cm} /$ year based on preoperative images, hemiarch operation was performed. In patients with connective tissue disorders, we concomitantly replaced the hemiarch if the diameter of any section of the distal ascending aorta was $\geq 4.0 \mathrm{~cm}$.

Moderate hypothermia (lowest temperature, $23.7^{\circ} \mathrm{C} \pm 2.2^{\circ} \mathrm{C}$ ) with ACP was used for all patients who underwent proximal arch replacement but one. The open distal anastomosis was a beveled hemiarch anastomosis that undercut the inferior portion of the transverse arch completely opposite to the take-off site of the left subclavian artery or opposite to the left common carotid artery if the left subclavian artery was too far. Near-infrared spectroscopy was used for cerebral monitoring. When circulatory arrest was initiated with ACP, the flows were decreased to $1.5 \mathrm{~mL} / \mathrm{kg} / \mathrm{min}$. Adjustment of the flows was dictated by near-infrared spectroscopy. In patients who had hemiarch repair, we performed the root dissection and, in some cases, placed the valvular sutures during the cooling phase if time allowed. We completed the root procedure during the rewarming period.

When the target temperature was achieved, the open distal anastomosis was performed with a continuous 3.0 or 4.0 polypropylene suture, followed by interrupted pledgeted sutures for reinforcement. For patients with ascending aortic repair only, the aorta was opened and tailored to an appropriate length after the crossclamp was applied. A Dacron graft was sutured to the distal ascending aorta. Cases of ARR involving a modified Bentall operation were performed with the use of a Valsalva mechanical composite valved graft (CVG; St Jude Medical, Inc, St Paul, Minn; $\mathrm{n}=56$ ); a bioprosthetic porcine root (Freestyle aortic root bioprosthesis; Medtronic Inc, Minneapolis, Minn; $\mathrm{n}=42$ ), or a handmade bioprosthetic CVG (constructed by sewing a Trifecta valve [St Jude Medical] to the

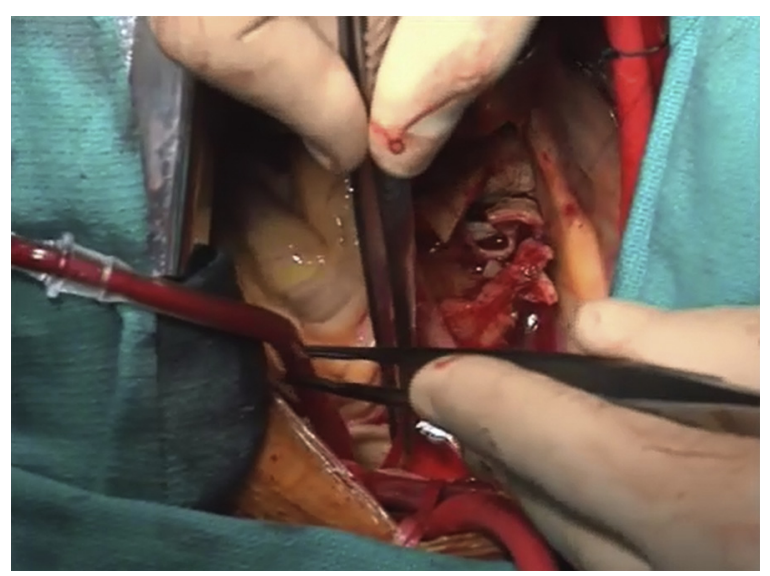

VIDEO 1. Hemiarch replacement and aortic valve-sparing procedure under moderate hypothermia. Video available at: http://www.jtcvsonline. org/article/S0022-5223(16)31483-0/addons. 
TABLE 1. Preoperative and demographic characteristics

\begin{tabular}{lccc}
\hline \multicolumn{1}{c}{ Characteristics } & Values overall $(\mathbf{n}=\mathbf{1 4 0})$ & Values without hemiarch repair $(\mathbf{n}=\mathbf{2 1})$ & Values with hemiarch repair $(\mathbf{n}=\mathbf{1 1 9})$ \\
\hline Age, $\mathrm{y}$ & $53.5(42.5-61.0)$ & $38.0(23.0-53.0)$ & $56.0(45.0-62.0)$ \\
Female & $29(20.7)$ & $11(52.4)$ & $18(15.1)$ \\
NYHA class III/IV & $9(6.4)$ & $2(9.5)$ & $7(5.9)$ \\
Genetic disease & $34(24.3)$ & $15(71.4)$ & $19(16.0)$ \\
BAV & $59(42.1)$ & $4(19.1)$ & $5(46.2)$ \\
Hypertension & $100(71.4)$ & $9(42.9)$ & $91(76.5)$ \\
Coronary artery disease* & $21(15.0)$ & $2(9.5)$ & $19(16.0)$ \\
Atrial arrhythmia/heart block & $28(20.0)$ & $5(23.8)$ & $23(19.3)$ \\
Pulmonary disease $\dagger$ & $24(17.1)$ & $4(19.1)$ & $20(16.8)$ \\
Cerebrovascular disease $†$ & $5(3.6)$ & $0(0.0)$ & $5(4.2)$ \\
Prior distal surgery & $8(5.7)$ & $1(4.8)$ & $7(5.9)$ \\
Mid ascending aortic diameter $§$ & $5.2 \pm 0.9$ & $5.2 \pm 0.7$ & $5.2 \pm 0.9 \|$ \\
Aortic root diameter $§$ & $5.1 \pm 0.8$ & $5.0 \pm 0.9$ & $5.1 \pm 0.8$ \\
\hline
\end{tabular}

Values are median (25\%-75\% interquartile range) for continuous variables and $\mathrm{n}(\%)$ for categorical variables unless otherwise noted. NYHA, New York Heart Association; $B A V$, bicuspid aortic valve. *Coronary artery disease was defined as history of angina or myocardial infarction or percutaneous transluminal coronary angioplasty/stent. $\dagger$ Pulmonary disease was defined as history of asthma or chronic obstructive pulmonary disease/emphysema/chronic bronchitis or restrictive lung disease. $\ddagger$ Cerebrovascular disease was defined as history of stroke or transient ischemic attack. §Values are mean \pm standard deviation. $\|$ Measurements of the distal ascending aorta for the hemiarch group were not taken.

bottom portion of a Gelweave Dacron graft; $n=1$ ). Valve-sparing ARR was performed in 41 patients.

For the mechanical CVG and the handmade bioprosthetic CVG, interrupted horizontal mattress pledgeted valve sutures were used to secure the CVG into the aortic annulus. For the Medtronic Freestyle bioprosthetic root, a 2.0 or 3.0 polypropylene continuous suture was used to secure the porcine root into the annulus. The left coronary button was then mobilized adequately and implanted in the body of the Dacron graft (mechanical or bioprosthetic CVG) or in the body of the Medtronic Freestyle porcine root. The Dacron graft for ascending aortic replacement or hemiarch reconstruction was tailored to an appropriate length and implanted with a continuous 3.0 or 4.0 polypropylene suture into the root graft (mechanical or bioprosthetic CVG) or the porcine root.

When ascending aortic repair alone was performed with the mechanical CVG, the Dacron graft attached to the conduit was used for the repair. The median size of the distal grafts used for the ascending anastomosis was
$24 \mathrm{~mm}$ (IQR 22-26 mm). The already-mobilized right coronary button was then attached to the body of the Dacron graft (mechanical or bioprosthetic CVG) or the body of the Medtronic Freestyle root. After deairing had been achieved, the aortic crossclamp was released. The patient was weaned from $\mathrm{CPB}$ when the body temperature reached $36.5^{\circ} \mathrm{C}$.

Our technique for valve-sparing ARR has been described previously. ${ }^{6}$ We use the Valsalva nonvalved root graft (Vascutek Ltd, Inchinnan, Renfrewshire, Scotland). To summarize, 6 subannular sutures are placed in the base of the aortic root Valsalva graft. A 4.0 polypropylene suture is placed in each valve commissure. After the root graft is cut to the appropriate length, the valve commissures and the leaflets are positioned inside the graft. The subannular sutures are tied. The valve commissures are secured near the top of the graft, and the supra-annular aortic tissue is sewn to the graft. We then continue with the attachment of the left coronary button, the graft-to-graft (root graft to ascending graft) anastomosis, and the right coronary button (Video 1).

TABLE 2. Intraoperative details

\begin{tabular}{|c|c|c|c|}
\hline Intraoperative details & $\begin{array}{l}\text { Values overall } \\
\qquad(\mathbf{n}=140)\end{array}$ & $\begin{array}{l}\text { Values without hemiarch } \\
\text { repair }(n=21)\end{array}$ & $\begin{array}{l}\text { Values with hemiarch } \\
\text { repair }(n=119)\end{array}$ \\
\hline \multicolumn{4}{|l|}{ Procedures } \\
\hline \multicolumn{4}{|l|}{ ARR } \\
\hline Valve-sparing, reimplantation & $41(29.3)$ & $3(14.3)$ & $38(31.9)$ \\
\hline CVG, mechanical & $56(40.0)$ & $12(57.1)$ & $44(37.0)$ \\
\hline CVG, tissue-bioroot & $1(0.7)$ & $0(0.00)$ & $1(0.8)$ \\
\hline Stentless tissue & $42(30.0)$ & $6(28.6)$ & $36(30.3)$ \\
\hline \multicolumn{4}{|l|}{ Concomitant procedures } \\
\hline CABG & $18(12.9)$ & $3(14.3)$ & $15(12.6)$ \\
\hline All cardiac* & $46(32.0)$ & $8(38.1)$ & 38 (31.9) \\
\hline \multicolumn{4}{|l|}{ Intraoperative adjuncts } \\
\hline CPB time, min & $149.0(128.0-178.0)$ & $160.0(138.0-193.0)$ & $148.0(125.0-176.0) \dagger$ \\
\hline Cardiac ischemic time, $\min$ & $114.0(94.5-135.0)$ & $114.0(94.0-142.0)$ & $114.0(95.0-134.0)$ \\
\hline Antegrade cerebral perfusion time, min & $18.0(15.0-21.0)$ & - & $18.0(15.0-21.0)$ \\
\hline PRBC transfused, units & $0(0-1)$ & $1(0-2)$ & $0(0-0)$ \\
\hline
\end{tabular}


TABLE 3. Short-term complications

\begin{tabular}{lccc}
\hline \multicolumn{1}{c}{ Complication } & Overall $(\mathbf{n}=\mathbf{1 4 0})$ & Without hemiarch repair $(\mathbf{n}=\mathbf{2 1})$ & With hemiarch repair $(\mathbf{n}=\mathbf{1 1 9})$ \\
\hline Postoperative stroke, transient & $2(1.4)$ & $2(9.5)$ & $0(0.0)$ \\
Renal failure requiring hemodialysis, transient & $1(0.7)$ & $1(4.8)$ & $0(0.0)$ \\
Reoperation for bleeding & $4(2.9)$ & $0(0.0)$ & $4(3.4)$ \\
Heart block requiring pacemaker & $14(10.0)$ & $3(14.3)$ & $11(9.2)$ \\
Pericardial effusion requiring drainage & $9(6.4)$ & $0(0.0)$ & $9(7.6)$ \\
Mechanical ventilation $>48$ h & $12(8.6)$ & $2(9.5)$ & $10(8.4)$ \\
Tracheostomy & $4(2.0)$ & $2(9.5)$ & $2(1.7)$ \\
Postoperative renal insufficiency & $3(2.1)$ & $1(4.8)$ & $2(1.7)$ \\
Composite adverse event* & $19(13.6)$ & $3(14.3)$ & $16(13.5)$ \\
Postoperative ICU LOS & $2(2-4)$ & $4(2-6)$ & $2(2-3)$ \\
Postoperative LOS, local & $8(6-10)$ & $9(7-13)$ & $7(6-9)$ \\
Disposition, home & $130(92.9)$ & $20(95.2)$ & $110(92.4)$ \\
Disposition, nursing home/SNF & $2(1.4)$ & $0(0.0)$ & $2(1.7)$ \\
Disposition, rehabilitation & $5(3.8)$ & $0(0.0)$ & $5(4.2)$ \\
Disposition, acute care or LTAC transfer & $3(2.1)$ & $1(4.8)$ & $2(1.7)$
\end{tabular}

Values are median ( $25 \%-75 \%$ interquartile range) for continuous variables and n (\%) for categorical variables. ICU, Intensive care unit; $L O S$, length of stay; SNF, skilled nursing facility; $L T A C$, long-term acute care. *Composite adverse event was defined as transient postoperative stroke or transient renal failure requiring hemodialysis or reoperation for bleeding or pericardial effusion requiring drainage or tracheostomy or postoperative renal insufficiency. Few patients had more than one postoperative complication.

\section{Statistical Analysis}

The differences in the distribution of preoperative, operative, and postoperative characteristics in the hemiarch and the no-hemiarch repair groups were tested with $\chi^{2}$ analysis, or the Fisher exact test when necessary, for the categorical variables. The nonparametric Wilcoxon 2 -sample test was used for the continuous variables. In addition, these tests were used in a univariate analysis to examine the effect of preoperative and operative risk factors on adverse events after surgery. A multivariate logistic regression model with the stepwise variable selection option was then applied to further explore the effect of the univariately significant risk factors on adverse events $(P<.1)$.

The following 19 preoperative and operative variables were used for this analysis: hemiarch repair, type of procedure (valve-sparing, mechanical, tissue/bioroot, or stentless tissue), age, sex, New York Heart Association class III/IV status, genetic disease, bicuspid aortic valve (BAV), hypertension, coronary artery disease, preoperative renal disease, atrial arrhythmia/heart block, pulmonary disease, cerebrovascular disease, previous distal [aortic] surgery, concomitant coronary artery bypass grafting (CABG), concomitant cardiac procedures, $\mathrm{CPB}$ time, cardiac ischemic time, and ACP time (only for the hemiarch procedure model). Multicollinearity was checked with regression analysis. Statistical analyses were performed with SAS version 9.1 (SAS Institute Inc, Cary, NC), and $P<.05$ was considered significant.

\section{RESULTS}

No 30-day or in-hospital mortality occurred. Two patients had a transient stroke; neither of them had undergone a hemiarch repair. Both strokes were ischemic and nonhemorrhagic. Table 3 shows the shortterm complications.

\section{Composite Adverse Outcome}

Because of the small number of adverse events, we grouped the following variables into a composite adverse outcome: transient stroke, renal failure with transient hemodialysis, postoperative renal insufficiency, postoperative bleeding requiring operation, pericardial effusion requiring drainage, and tracheostomy. A total of 16 patients in the hemiarch group $(13.5 \%)$ and 3 patients in the ascending aortic group $(14.3 \%)$ experienced a composite adverse outcome. Stroke was the only adverse event that had a greater incidence in the ascending group in the univariate analysis only (Table 3 ). Multivariate analysis for all patients showed that concomitant $\mathrm{CABG}$ appeared to be associated with a composite adverse outcome $(P=.013$; odds ratio, $4.19 ; 95 \%$ confidence interval, 1.35-13.06). (Tables 4 and 5). The CABG procedures were planned in advance $(\mathrm{n}=15 ; 83.3 \%)$ except for 3 patients. In these 3 patients ( 1 in the ascending aortic group who had a CVG; and 2 patients in the hemiarch group, 1 who had a valve-sparing root procedure and the other who had a stentless tissue root), CABG was a rescue strategy due to right ventricular failure. When we excluded the 3 patients with a rescue CABG from our cohort in the subgroup multivariate analysis, the cardiac ischemia time predicted the composite adverse event in the entire group (Table 5).

\section{Follow-up Evaluation}

For all patients, the median follow-up period for any adverse event was 26 months (IQR 14.2-38.2 months). Two patients required surgical reintervention at our institution during the follow-up period. To our knowledge, no other patient required another surgical intervention during the follow-up period. One patient from the ascending aortic replacement group $(4.8 \%)$ required endovascular repair of the infrarenal aorta 3 months after the index procedure. The patient was admitted 2 years later with prosthetic valve endocarditis and underwent redo homograft root replacement and proximal arch replacement for dilated hemiarch. This patient is still alive 21 months 
TABLE 4. Univariate analysis for composite adverse events for all patients and for the hemiarch patients

\begin{tabular}{|c|c|c|c|c|c|c|}
\hline \multirow[b]{2}{*}{ Variable } & \multicolumn{3}{|c|}{ All patients adverse events $(n=140)$} & \multicolumn{3}{|c|}{ Patients with hemiarch repair adverse events $(n=119)$} \\
\hline & No $(n=121)$ & Yes $(\mathbf{n}=19)$ & $P$ value & No $(n=103)$ & Yes $(\mathbf{n}=16)$ & $P$ value \\
\hline Previous distal surgery & $5(62.5)$ & $3(37.5)$ & .077 & $4(57.1)$ & $3(42.9)$ & .050 \\
\hline Cardiac ischemic time & $114(94-131)$ & $125(97-168)$ & .078 & $114.0(94-131)$ & $123.5(97.5-139.5)$ & .17 \\
\hline Concomitant CABG & $12(66.7)$ & $6(33.3)$ & .018 & $8(57.1)$ & $6(42.9)$ & .0036 \\
\hline All concomitant cardiac procedures* & $35(76.1)$ & $11(23.9)$ & .012 & $29(76.3)$ & $9(23.7)$ & .025 \\
\hline
\end{tabular}

Values are median ( $25 \%-75 \%$ interquartile range) for continuous variables and $\mathrm{n}(\%)$ for categorical variables. CABG, Coronary artery bypass grafting. *All concomitant cardiac procedures was defined as concomitant CABG and other aortic procedures: aortic valve annuloplasty, mitral valve repair/replacement, tricuspid valve repair, aortic valve annuloplasty, maze procedure, atrial/ventricular septal defect repair, patent foreman ovale repair, and coronary artery bypass.

after the second procedure. The other patient who required reintervention $(0.8 \%)$ had undergone hemiarch repair. This patient had Marfan syndrome and previous endovascular repair of the descending thoracic aorta for acute type III aortic dissection. This patient required extent III thoracoabdominal aortic replacement with removal of the endograft because of an enlarging false lumen.

\section{DISCUSSION}

The literature does not include enough data for extensive proximal arch repair to be recommended for patients with ARR. ${ }^{7}$ The 2010 American College of Cardiology Foundation/American Heart Association/ American Association for Thoracic Surgery/American College of Radiology/American Stroke Association/Society of Cardiovascular Anesthesiologists/Society for Cardiac Angiography and Interventions/Society of Interventional Radiology/Society of Thoracic Surgeons/Society for Vascular Medicine guidelines for the diagnosis and management of patients with thoracic aortic disease do not specify the extent of aortic resection needed in patients who are undergoing elective ARR. ${ }^{8}$ The current recommendations state that "[p] atients undergoing aortic valve repair or replacement and who have an ascending aorta or aortic root of greater than $4.5 \mathrm{~cm}$ should be considered for concomitant repair of the aortic root or replacement of the ascending aorta (Class I, Level of Evidence: C)." ${ }^{8}$ In addition, the current recommendations state that "[a]scending aneurysms larger than 4.5 to $5.0 \mathrm{~cm}$ require repair or tube graft replacement

TABLE 5. Multivariate analysis for composite adverse events for all patients

\begin{tabular}{|c|c|c|}
\hline \multirow[b]{2}{*}{ Variable } & \multicolumn{2}{|c|}{ Overall } \\
\hline & $P$ value & OR $(95 \% \mathbf{C I})^{*}$ \\
\hline Concomitant CABG & .013 & $4.19(1.35-13.06)$ \\
\hline \multicolumn{3}{|c|}{ Sensitivity analysis for planned concomitant CABG } \\
\hline Cardiac ischemia time & .022 & $1.02(1.00-1.03)$ \\
\hline \multicolumn{3}{|c|}{$\begin{array}{l}\text { Values are OR }(95 \% \mathrm{CI}) . O R \text {, Odds ratio; } C I \text {, confidence interval; } C A B G \text {, coronary } \\
\text { artery bypass grafting. *All concomitant cardiac procedures was defined as } \\
\text { concomitant } \mathrm{CABG} \text { and other aortic procedures: aortic valve annuloplasty, mitral } \\
\text { valve repair/replacement, tricuspid valve repair, aortic valve annuloplasty, maze } \\
\text { procedure, atrial/ventricular septal defect repair, patent foreman ovale repair, and } \\
\text { coronary artery bypass. }\end{array}$} \\
\hline
\end{tabular}

when aortic valve repair or replacement is the primary indication for operation." 8

In our study, we investigated whether extending repair into the proximal aortic arch after elective ARR increased the risk for adverse events. Malaisrie and colleagues ${ }^{7}$ showed that the addition of hemiarch repair to aortic root surgery did not affect operative mortality and safety, nor did it add significant morbidity to the operation. In their study, propensity score matching of 133 pairs of patients undergoing hemiarch repair versus ascending aortic replacement alone showed that the 30-day mortality rate was equal in both groups $(3 \%$ vs $1.5 \% ; P=.41) .{ }^{7}$ No operative deaths were observed in our study, and this difference can potentially be explained by the fact that Malaisrie and colleagues included pairs of 21 redo sternotomy patients and that not all procedures were elective.

In our ascending aorta-only group, we noticed a tendency toward a greater rate of temporary stroke that was similar to the findings of Malaisrie and colleagues. ${ }^{7}$ Nevertheless, no significant difference with regards to neurologic events was found between the 2 groups in either study. In our hemiarch group, the mean ACP time was 18 minutes, which is below the "window" of 25 minutes or more in which neurologic deficits, as well as mortality, can occur. ${ }^{5,9}$ This brief period of ACP could explain the absence of strokes or mortality in our group. This finding is extremely important in considering a more extended aortic repair towards the proximal arch.

Reoperation for bleeding occurred only in our hemiarch group and may have been due to dysfunction of the coagulation cascade during $\mathrm{CPB}$, which is exacerbated by hypothermia during HCA. This difference was not significant when the hemiarch group was compared with the ascending aorta-only group; a similar finding was reported by Malaisrie and colleagues. ${ }^{7}$ Hemostatic disturbances and coagulation problems have been reported with HCA use. ${ }^{10}$ Careful hemostasis is warranted if the aortic root surgery is associated with proximal hemiarch operations.

In cases involving a BAV, there is a long-standing debate about the surgical threshold for associated aortopathy. ${ }^{11-14}$ In our series, BAV was observed more often in patients who underwent hemiarch replacement $(46.2 \%)$ than in patients who had ascending aortic replacement (19.1\%). 
According to the recent guidelines for surgery of the ascending aorta and the aortic valve, patients with BAV should undergo surgery if the diameter of the ascending aorta is greater than $5 \mathrm{~cm}$. If there is a family history of aortic dissection, that threshold is lowered to $4.5 \mathrm{~cm} .{ }^{15}$ In our practice, when performing aortic root surgery in a patient with BAV, we replace the distal ascending aorta if its diameter is $4.0 \mathrm{~cm}$ or larger. This may explain why we had more patients with BAV in the hemiarch group.

The ascending aorta-only replacement group was younger than the hemiarch group because the ascending aorta-only group had more patients with genetically triggered thoracic aortic disease, who usually are relatively younger. In general, when we perform an elective root replacement in a patient with a connective tissue disorder, we are aggressive in replacing the proximal arch if the ascending aorta is dilated more than $4.0 \mathrm{~cm}$ or if there is a family history of aneurysms or dissections. Although the age difference between our 2 groups was significantly different, both groups were young and expected to respond in a similar way clinically.

With respect to the composite adverse outcome, the need for concomitant $\mathrm{CABG}$, whether it was a planned or a bailout procedure, appeared to be a risk factor for adverse events in the hemiarch group. Further sensitivity analysis, which included only the planned CABG procedures, revealed that the cardiac ischemia time was associated with the composite adverse outcome in the entire group. Silva and colleagues ${ }^{16}$ reported that a prolonged CPB time was an independent predictor of major complications in patients undergoing primary and redo aortic root procedures. In addition, the need for CABG is one of the risk factors associated with in-hospital mortality in patients undergoing aortic root operations. ${ }^{16,17}$ We agree with others $^{16,17}$ that concomitant CABG during elective, non-redo aortic root operations are associated with increased morbidity. Patients who require concomitant CABG are considered a high-risk group. ${ }^{18,19}$ In a series reported by Byrne and colleagues, ${ }^{19}$ the operative mortality in patients with planned CABG (18 of 87 patients; $21 \%$ ) versus the mortality in patients with no need for CABG plus those who needed a CABG bailout ( 3 of 282 patients; $1 \%$ ) was significant. Presumed misalignment of the coronary button (right or left) during implantation results in left or right ventricular failure, which necessitates concomitant $\mathrm{CABG}$. In our series, $3 \mathrm{CABG}$ procedures were done as part of a rescue strategy; when they were excluded from the analysis, however, the planned concomitant $\mathrm{CABG}$ procedures continued to predict morbidity for the hemiarch group.

Furthermore, aggressive resection of the entire diseased aortic segment may minimize the need for future reoperation. ${ }^{18}$ Although our study focused on the effect of the surgical intervention on short-term clinical outcomes,
2 patients ( 1 in the ascending group and 1 in the hemiarch group) underwent subsequent surgery. With regard to the patient in the hemiarch group who had Marfan syndrome, the distal aortic intervention was expected and planned. However, firm conclusions are difficult to draw because of the small number of patients.

The main limitations of our study are its retrospective and observational nature and the small overall sample size. Because of the small number of patients who underwent only ascending aortic repair, the 2 groups were not compared; for the same reason, propensity matching score analysis was not performed. In addition, the true value of performing a hemiarch replacement can be determined only by comparing long-term rates of reintervention in the aortic arch between the 2 groups; therefore, we reported only early outcomes in this study. Nevertheless, ours is one of the few studies to focus on the safety of proximal aortic arch repair in patients with no previous cardiac surgery who are undergoing elective aortic root surgery. To avoid potential future aortic enlargement, we initially will approach non-redo, elective, primary aortic root operations by performing relatively aggressive aortic resection for root aneurysms that extend into the distal aorta.

\section{CONCLUSIONS}

In conclusion, the additional ACP time required for performing a hemiarch replacement in patients undergoing elective ARR usually is brief and not associated with mortality or serious neurologic events. Concomitant CABG can increase morbidity in patients who are undergoing elective primary ARR regardless of additional proximal arch replacement. Correct placement of the coronary buttons (right or left) to avoid misalignmentwhich can lead to left or right ventricular failure-is important. Hemiarch repair did not play a significant role with regard to any adverse events, but these results should be interpreted cautiously because of the small number of patients. Hemiarch repair should be considered when needed in patients undergoing an elective, primary root operation. To firmly draw conclusions, we need longer follow-up observation to evaluate the rate of reoperation involving the transverse arch in patients who undergo only ascending aortic replacement with aortic root surgery. We and others have shown that including a beveled hemiarch in patients who are undergoing root replacement electively has minimal associated risk. Current guidelines do not address this issue. Our findings should be confirmed in a larger, multi-institutional patient series.

\section{Conflict of Interest Statement}

Dr Coselli serves as PI for ongoing clinical trials with Edwards LifeSciences, Medtronic, Inc, and W. L. Gore \& Associates. He also consults with Vascutek Terumo, 
Medtronic, Inc, and W. L. Gore \& Associates. Dr Preventza is also a consultant for Medtronic, Inc, and W. L. Gore \& Associates. All other authors have nothing to disclose with regard to commercial support.

The Section of Scientific Publications at the Texas Heart Institute contributed to the editing of the manuscript.

\section{References}

1. Dossche KM, Tan ME, Schepens MA, Morshuis WJ, de la Riviere AB. Twenty-four year experience with reoperations after ascending aortic or aortic root replacement. Eur J Cardiothorac Surg. 1999;16:607-12.

2. Preventza O, Price MD, Simpson KH, Cooley DA, Pocock E, de la Cruz KI, et al. Hemiarch and total arch surgery in patients with previous repair of acute type I aortic dissection. Ann Thorac Surg. 2015;100:833-8.

3. Moon MR, Sundt TM 3rd, Pasque MK, Barner HB, Huddleston CB Damiano RJ Jr, et al. Does the extent of proximal or distal resection influence outcome for type A dissections? Ann Thorac Surg. 2001;71:1244-9; discussion $9-50$.

4. Ehrlich MP, Ergin MA, McCullough JN, Lansman SL, Galla JD, Bodian CA, et al. Predictors of adverse outcome and transient neurological dysfunction after ascending aorta/hemiarch replacement. Ann Thorac Surg. 2000;69: 1755-63.

5. Reich DL, Uysal S, Sliwinski M, Ergin MA, Kahn RA, Konstadt SN, et al Neuropsychologic outcome after deep hypothermic circulatory arrest in adults J Thorac Cardiovasc Surg. 1999;117:156-63.

6. Coselli JS, Hughes MS, Green SY, Price MD, Zarda S, de la Cruz KI, et al Valve-sparing aortic root replacement: early and midterm outcomes in 83 patients. Ann Thorac Surg. 2014;97:1267-73; discussion 73-4.

7. Malaisrie SC, Duncan BF, Mehta CK, Badiwala MV, Rinewalt D, Kruse J, et al The addition of hemiarch replacement to aortic root surgery does not affect safety. J Thorac Cardiovasc Surg. 2015;150:118-24.e2.

8. Hiratzka LF, Bakris GL, Beckman JA, Bersin RM, Carr VF, Casey DE Jr, et al 2010 ACCF/AHA/AATS/ACR/ASA/SCA/SCAI/SIR/STS/SVM guidelines for the diagnosis and management of patients with thoracic aortic disease: a report of the American College of Cardiology Foundation/American Heart Association Task Force on Practice Guidelines, American Association for Thoracic Surgery, American College of Radiology, American Stroke Association, Society of Cardiovascular Anesthesiologists, Society for Cardiovascular Angiography and
Interventions, Society of Interventional Radiology, Society of Thoracic Surgeons, and Society for Vascular Medicine. Circulation. 2010;121:e266-369.

9. Svensson LG, Crawford ES, Hess KR, Coselli JS, Raskin S, Shenaq SA, et al. Deep hypothermia with circulatory arrest. Determinants of stroke and early mortality in 656 patients. J Thorac Cardiovasc Surg. 1993;106:19-28; discussion 28-31.

10. Wilde JT. Hematological consequences of profound hypothermic circulatory arrest and aortic dissection. J Card Surg. 1997;12:201-6.

11. Rinewalt D, McCarthy PM, Malaisrie SC, Fedak PW, Andrei AC, Puthumana JJ, et al. Effect of aortic aneurysm replacement on outcomes after bicuspid aortic valve surgery: validation of contemporary guidelines. J Thorac Cardiovasc Surg. 2014;148:2060-9.

12. Hardikar AA, Marwick TH. Surgical thresholds for bicuspid aortic valve associated aortopathy. JACC Cardiovasc Imaging. 2013;6:1311-20.

13. Svensson LG, Kim KH, Blackstone EH, Rajeswaran J, Gillinov AM, Mihaljevic T, et al. Bicuspid aortic valve surgery with proactive ascending aorta repair. J Thorac Cardiovasc Surg. 2011;142:622-9. 629.e1-3.

14. Park CB, Greason KL, Suri RM, Michelena HI, Schaff HV, Sundt TM 3rd. Should the proximal arch be routinely replaced in patients with bicuspid aortic valve disease and ascending aortic aneurysm? J Thorac Cardiovasc Surg 2011;142:602-7.

15. Svensson LG, Adams DH, Bonow RO, Kouchoukos NT, Miller DC, O'Gara PT, et al. Aortic valve and ascending aorta guidelines for management and quality measures: executive summary. Ann Thorac Surg. 2013;95:1491-505.

16. Silva J, Maroto LC, Carnero M, Vilacosta I, Cobiella J, Villagran E, et al Ascending aorta and aortic root reoperations: are outcomes worse than first time surgery? Ann Thorac Surg. 2010;90:555-60.

17. Etz CD, Bischoff MS, Bodian C, Roder F, Brenner R, Griepp RB, et al. The Bentall procedure: is it the gold standard? A series of 597 consecutive cases. J Thorac Cardiovasc Surg. 2010;140:S64-70; discussion S86-91.

18. Rylski B, Milewski RK, Bavaria JE, Vallabhajosyula P, Moser W, Szeto WY, et al. Long-term results of aggressive hemiarch replacement in 534 patients with type A aortic dissection. J Thorac Cardiovasc Surg. 2014;148:2981-5.

19. Byrne JG, Karavas AN, Leacche M, Unic D, Rawn JD, Couper GS, et al. Impact of concomitant coronary artery bypass grafting on hospital survival after aortic root replacement. Ann Thorac Surg. 2005;79:511-6.

Key Words: elective aortic root replacement, hypothermic circulatory arrest, antegrade cerebral perfusion, proximal aortic arch, aortic aneurysm, early outcomes, hemiarch replacement 